\title{
Rwanda Human Resources for Health Program: Genesis and Evolution of the Nursing and Midwifery Program
}

\author{
Glorieuse Uwizeye ${ }^{1}$, Anne M Sliney² \\ ${ }^{1}$ Ministry of Health, Rwanda \\ ${ }^{2}$ Clinton Health Access Initiative, US A
}

\section{Background}

In 2010, the Permanent Secretary of the Rwanda Ministry of Health reached out to select US schools of nursing and midwifery to request support for a program to dramatically improve nursing and midwifery education and practice. This poster described the process that led to the Rwanda HRH Program, how nursing and midwifery leadership determined and communicated their needs, and how they crafted and continue to craft the program to meet their goals.

\section{Description}

Rwandan nursing and midwifery leaders met with representatives of the US schools in April of 2011. Over a 4 day period, they determined the number of educators they needed, what qualifications would be required, and what specific skills they should possess. Over the next 10 months, these two groups continued to refine the details of the program. US institutions began to recruit faculty, and systems were put in place for the Rwandan leadership to govern the program. The first group of educators (29) arrived in August of 2012. Over the next $2 \frac{1}{2}$ years, the program evolved to meet the changing needs of Rwandan nursing and midwifery. Program governance, priorities, roles of foreign and Rwandan faculty, and the structure of higher education for health professionals at the University of Rwanda have all changed, and the nursing and midwifery leadership has managed all of those changes.

\section{Lessons Learned}

Developing an effective partnership between national nursing leadership and foreign academic institutions requires flexibility, respect, and thoughtful planning.

\section{Conclusions}

The Rwanda HRH Nursing and Midwifery Program is a remarkable example of professional collaboration and capacity to evolve.

Key words: Rwanda HRH, Rwanda nursing and midwifery, nursing education 